\title{
Verslag WONO-symposium 25 januari 2019
}

\author{
Mr. K.J. Bakkeren mr. N. Kreileman*
}

Verslag van het symposium van de Stichting Wetenschappelijk Onderzoek (Notarieel) Ondernemingsrecht (WONO) van 25 januari 2019 met lezingen over loyaliteitsaandelen, waarderingsvragen in het ondernemingsrecht, dual classaandelen bij beursvennootschappen en 'Coding for Lawyers'.

\section{Inleiding}

Op 25 januari 2019 vond het jaarlijkse symposium van de Stichting Wetenschappelijk Onderzoek (Notarieel) Ondernemingsrecht (WONO) plaats. Net als voorgaande jaren werd het symposium gehouden in een voormalige kerk in Amsterdam, waar thans de Stichting tot Bevordering der Notariële Wetenschap kantoor houdt. Tijdens het symposium, dat werd voorgezeten door Niek Zaman, presenteerden drie promovendi hun promotieonderzoek op het terrein van het ondernemingsrecht aan een gemêleerd gezelschap van promovendi, hoogleraren, wetgevingsjuristen, (kandidaat-)notarissen, advocaten en vertegenwoordigers van beroepsorganisaties. Professor Erik Vermeulen sloot het symposium af met een inspirerend verhaal over 'Coding for Lawyers'. In deze bijdrage doen wij op hoofdlijnen verslag van het symposium.

\section{Bart Bootsma over loyaliteitsaandelen}

Bart Bootsma trapte de middag af met een presentatie over zijn promotieonderzoek naar loyaliteitsaandelen bij beursgenoteerde NV's. ${ }^{1}$ Dit onderwerp staat al sinds de DSM-zaak in de belangstelling en is vandaag de dag nog altijd actueel. ${ }^{2}$ In de voortgangsbrief over de modernisering van het ondernemingsrecht van 20 december 2018 gaat minister Dekker namelijk ook in op het onderwerp loyaliteitsaandelen. ${ }^{3}$ In het bijzonder vraagt de minister zich af of een wettelijke regeling voor dubbel stemrecht naar Frans voorbeeld ook in Nederland wense-

Mr. K.J. Bakker is als promovendus en docent (notarieel) ondernemingsrecht verbonden aan het Van der Heijden Instituut (OO\&R) van de Radboud Universiteit Nijmegen. Mr. N. Kreileman is als promovenda en docente ondernemingsrecht verbonden aan het Van der Heijden Instituut (OO\&R) van de Radboud Universiteit Nijmegen. Daarnaast is zij redacteur van $\mathrm{MvO}$.

1. Mr. drs. A.A. (Bart) Bootsma is werkzaam als wetenschappelijk medewerker bij de Hoge Raad. Hij was voorheen als onderzoeker, promovendus en docent verbonden aan de Sectie Ondernemingsrecht \& Financieel recht van de Erasmus Universiteit Rotterdam. Hij is redacteur van $\mathrm{MvO}$.

2. HR 14 december 2007 , NJ 2008/105, JOR 2008/11, Ondernemingsrecht 2008/11 (DSM). Zie ook K.J. Bakker, Loyaliteitsregelingen; lessen uit Frankrijk en Delaware, MvO 2019, afl. 1.

3. Zie Kamerstukken II 2018/19, 29752, 12. lijk is. Deze vraag beantwoordt hij ontkennend. Het lijkt hem onwenselijk om - zoals in Frankrijk - meervoudig stemrecht als uitgangspunt (default) te nemen. Dat is Bootsma met hem eens. De minister stelt dat met de voorgestelde wettelijke bedenktijd een betere balans tussen (minderheids)aandeelhouders en bestuur van de vennootschap kan worden gevonden. Daar denkt Bootsma echter anders over. ${ }^{4}$

Hoewel een wettelijke regeling ontbreekt, komen loyaliteitsaandelen - in de praktijk ook wel bijzondere stemrechtaandelen ('Special Voting Shares') genoemd - thans bij vier Nederlandse vennootschappen voor: $\mathrm{CNH}$ Industrial NV, Fiat Chrysler Automobiles NV, Ferrari NV en EXOR NV. Bootsma heeft de statuten van deze vennootschappen uitgeplozen. De redenen voor invoering van loyaliteitsaandelen bij deze vier vennootschappen blijken veelzijdig te zijn. Het gaat niet alleen om het belonen van langetermijnaandeelhouderschap, maar met het dubbele stemrecht kan bijvoorbeeld ook bereikt worden dat een verplichting tot het uitbrengen van een openbaar bod op alle uitstaande aandelen ontstaat.

Bootsma besprak vervolgens de wijze waarop deze vier Nederlandse vennootschappen vorm hebben gegeven aan loyaliteitsaandelen. Deze vennootschappen hebben in de statuten een aparte soort loyaliteitsaandelen gecreëerd. De statuten bevatten verder een grondslag voor een loyaliteitsreglement, waarin onder andere de voorwaarden voor aanspraak op loyaliteitsaandelen zijn opgenomen. De kern daarvan is dat een aandeelhouder die zijn aandelen een $\mathrm{x}$-aantal jaren houdt, één of meer extra aandelen krijgt. Deze worden volgestort uit een bijzondere statutaire reserve. De loyale aandeelhouder krijgt de facto dus meer stemrecht, maar formeel wordt niet aan het uitgangspunt 'one share, one vote' getornd. Aan elk aandeel zijn immers in verhouding tot de nominale waarde dezelfde hoeveelheden stemmen verbonden, maar loyale aandeelhouders krijgen eenvoudigweg meer aandelen. Omdat een wettelijke regeling niet voorhanden is, is het thans onduidelijk waar nu precies de grenzen liggen. Specifieke waarborgen zijn evenmin voorhanden.

4. Zie nader A.A. Bootsma, Over de toekomst van het vennootschapsrecht, in: H.J. de Kluiver (red.), 100 jaar Handelsrecht. Over heden, toekomst en verleden (Jubileumuitgave Vereeniging 'Handelsrecht' 1918-2018), Zutphen: Paris 2018, p. 114-118. 


\section{Maandblad}

Ondernemingsrecht

Fasolis dacht al in 1926 na over de waarborgen voor meervoudig stemrecht, zoals (nu) bij loyaliteitsaandelen. ${ }^{5} \mathrm{Hij}$ dacht bijvoorbeeld aan een minimale houdtermijn, een begrenzing aan de vermenigvuldigingsfactor voor het stemrecht (bijvoorbeeld maximaal twee keer) en uniforme behandeling van alle aandeelhouders bij invoering. Fasolis meent verder dat bij een midstream-invoering van meervoudig stemrecht aanvullende eisen moeten gelden, zoals een versterkte stemmenmeerderheid. Voorts kan bij invoering van loyaliteitsaandelen worden gedacht aan horizonbepalingen (sunset provisions). ${ }^{6}$ Dit zijn bepalingen die ertoe leiden dat de loyaliteitsaandelen of het loyaliteitsstemrecht automatisch vervallen na een bepaalde periode of als een bepaalde gebeurtenis zich voordoet. Volgens Bootsma kan een horizonbepaling nuttig zijn. Een 'one size fits all-benadering werkt voor loyaliteitsaandelen evenwel niet. Bovendien kennen loyaliteitsaandelen - anders dan dual classaandelen (zie par. 4) - doorgaans al een sunset provision, omdat het aanvullende stemrecht in de regel vervalt als de loyale aandeelhouder zijn aandelen vervreemdt.

Zou er een wettelijke regeling voor loyaliteitsaandelen moeten komen? Bootsma beantwoordt deze vraag bevestigend. Thans bestaat immers veel rechtsonzekerheid. Een wettelijke basis, waarin ook de grenzen worden aangegeven, kan die onzekerheid wegnemen.

\section{Sebastiaan van den Berg over waarderingsvragen in het ondernemingsrecht}

Vervolgens was het woord aan Sebastiaan van den Berg. ${ }^{7} \mathrm{Hij}$ sprak over waarderingsvragen in het ondernemingsrecht, hoewel zijn proefschrift ook het insolventierecht beslaat. Waarderingsvragen spelen niet alleen bij het opstellen van waarderingsrapporten in de herstructureringspraktijk, maar ook bij de geschillenregeling, de uitkoopprocedure, de blokkeringsregeling, de Interventiewet en bij afsplitsing. Steeds wordt echter een andere waarderingsmethode gebruikt. Zo wordt bij waarderingsrapporten in de herstructureringspraktijk aangesloten bij de reële waarde (fair value) of de reële marktwaarde (fair market value), terwijl bij de geschillenregeling en de uitkoopprocedure wordt gekeken naar de waarde in het economische verkeer (hierbij gaat het om de hoogst biedende partij). ${ }^{8}$ Laatstgenoemd begrip wijkt daarmee af van de Interventiewet, waarin wordt uitgegaan van de prijs die gegeven het betreffende toekomstperspectief op het tijdstip van onteigening tussen redelijk handelende partijen tot stand zou zijn

5. G. Fasolis, De bescherming der minderheden, Feestuitgave bij WPNR 1926/2947, p. 78-87.

6. Zie ook A.A. Bootsma, Loyaliteitsdividend, bijzondere stemrechtaandelen en de positie van minderheidsaandeelhouders. Midstream or IPO introduction, that's the question, $\mathrm{MvO}$ 2016, afl. 7, p. 151-160.

7. Mr. drs. S.W. (Sebastiaan) van den Berg is advocaat te Amsterdam. Op donderdag 31 januari 2019 promoveerde hij op een onderzoek naar waarderingsvragen in het ondernemings- en insolventierecht aan de Radboud Universiteit Nijmegen.

8. Zie voor de geschillenregeling: Hof Amsterdam (OK) 16 februari 2010, JOR 2010/96 (Hooymans). Zie voor de uitkoopprocedure: Hof Amsterdam (OK) 30 juli 2008, JOR 2008/197 (Euronext). gekomen. ${ }^{9}$ Weer anders is de maatstaf bij afsplitsing. Daar gaat het om de waarde van 'het vermogen' ${ }^{10} \mathrm{Bij}$ de blokkeringsregeling draait het tot slot om de werkelijke waarde van de aandelen. ${ }^{11}$ Maar wat is nu precies die werkelijke waarde? Uit een empirisch onderzoek dat Van den Berg in 2013 onder Register Valuators en corporate finance-professionals verrichtte, blijkt dat zelfs daar geen overeenstemming over bestaat. $81 \%$ van de ondervraagden nam de waarde van de aandelen in de 'as is'situatie (onder een going concern stand-alone-gedachte), $0 \%$ hanteerde de 'value in use voor de overnemende aandeelhouder' en $19 \%$ ging uit van de 'waarde die een derde aan het pakket zou toekennen': de waarde in het economische verkeer.

Een toch al arbitrair onderwerp zoals waardering kan snel tot rechtsonzekerheid leiden, zo blijkt uit het bovenstaande. Van den Berg vindt dat al die bijvoeglijke naamwoorden maar beperkte lading hebben. Daarom stelt hij voor minder nadruk te leggen op de terminologie (zoals 'objectieve' en 'werkelijke' waarde) en meer aandacht te bieden aan de context waarin moet worden gewaardeerd. Van den Berg introduceert in zijn proefschrift een waarderingskader dat toepasbaar is op elk waarderingsvraagstuk in het ondernemingsrecht. Dit waarderingskader bestaat uit vijf stappen. Allereerst moet het doel of de opdracht worden bepaald. Daarna dient de waarderingscontext of de waardemaatstaf te worden vastgesteld. Hierbij zijn er twee opties: de ruilwaarde (value in exchange) en de gebruikswaarde (value in use). Stap drie en vier zijn voor de deskundigen. $\mathrm{Zij}$ moeten het waardebegrip en vervolgens een daarbij passende waarderingsmethode bepalen. Stap vijf biedt tot slot ruimte voor correctie.

Van den Berg gaf ten slotte een concrete aanbeveling: het is efficiënter om de uiteindelijk (bij uittreding) in te schakelen waarderingsdeskundige van tevoren te bepalen dan waarderingsdeskundigen aan het begin van de samenwerking te laten adviseren over prijsbepalingsformules voor het toekomstige scenario van 'scheiding'. Weliswaar wordt met die formules enige zekerheid naar voren gehaald, maar ook dan kan bij de 'scheiding' nog veel discussie ontstaan over de neergelegde maatstaf en methode - aldus Van den Berg, sprekend uit eigen ervaring.

\section{Titiaan Keijzer over dual class-aandelen bij beursvennootschappen}

Tot slot sprak Titiaan Keijzer over zijn promotieonderzoek naar dual class-aandelen bij beursvennootschappen. ${ }^{12}$ Dual class-aandelen worden traditioneel kritisch bezien door economen. Kern van de kritiek is dat de agencykosten van een dual class-aandelenstructuur hoger zijn dan die van proportioneel stemrecht. Er zijn ook economen die dual class-aandelenstruc-

9. Zie art. 6:9 lid $1 \mathrm{Wft}$.

10. Zie art. 2:334w BW.

11. Zie o.a. Asser/Maeijer, Van Solinge \& Nieuwe Weme 2-II* 2009/291.

12. Mr. T.A. (Titiaan) Keijzer is als promovendus verbonden aan de Sectie Ondernemingsrecht \& Financieel recht van de Erasmus Universiteit Rotterdam. Daarnaast is hij redacteur van MvO. 
turen acceptabel vinden zolang de voordelen opwegen tegen de nadelen (de 'idiosyncratic vision'). ${ }^{13}$ Keijzer is het in beginsel met die laatste opvatting eens. Hij heeft in de financieeleconomische literatuur onderzocht in welke gevallen dual class-aandelen van meerwaarde kunnen zijn. Zo heeft Keijzer gekeken naar de benadering van Fama en French. ${ }^{14}$ Kern daarvan is dat niet één, maar verschillende factoren relevant zijn voor de vraag welke kapitaalstructuur het beste aansluit op de behoeften van vennootschappen. De weging van de respectievelijke factoren hangt af van de 'levensfase' waarin de onderneming zich bevindt: de factoren winnen of verliezen aan gewicht naarmate de onderneming groeit, verandert of krimpt.

Deze benadering kan ook op de verdeling van stemrechten worden toegepast. Aan het begin van het leven van een vennootschap zijn de informatiekosten hoog. Een dual class-aandelenstructuur kan dan waardevol zijn. Om het stemrecht bij de oprichters te concentreren, kunnen bijvoorbeeld enkel stemrechtloze aandelen aan externe investeerders worden uitgegeven, of kunnen de oprichters zichzelf aandelen met meervoudig stemrecht toekennen. De oprichters houden daardoor grip op de (nog snelgroeiende) onderneming. Na verloop van tijd neemt de behoefte aan de dual class-aandelenstructuur logischerwijs af, omdat de informatiekosten door professionalisering van de onderneming en toegenomen kennis bij beleggers dalen. Het kan dan in de rede liggen om de dual class-aandelenstructuur weer op te heffen. In een dergelijke, meer stabiele fase bestaat vanuit financieel-economisch perspectief immers minder rechtvaardiging om de dual class-aandelenstructuur in stand te houden.

De vraag die daarbij rijst, is of van tevoren al in de afbouw van de dual class-aandelenstructuur moet worden voorzien. Te denken valt aan het opnemen van een horizonbepaling in de statuten, inhoudende dat de dual class-aandelen vervallen door bijvoorbeeld tijdsverloop, vermindering van het kapitaalbelang van de controlerende aandeelhouder en/of een vooraf omschreven gebeurtenis. Keijzer vindt dit echter, zeker in dwingendrechtelijke vorm, geen goede aanpak. In de eerste plaats is het lastig een horizonbepaling statutair vorm te geven. Want wanneer is een vennootschap nu precies 'volwassen'? Ten tweede wordt het problematisch wanneer de controlerende aandeelhouder geen natuurlijk persoon, maar een organisatie is. Het argument dat de superieure vaardigheden van de controlerende aandeelhouder na verloop van tijd verminderen, gaat dan niet langer altijd op. Tot slot is in theorie denkbaar dat de eenmaal volwassen vennootschap de legacy business afsplitst, waardoor de life cycle van de vennootschap weer terugkomt in een eerder (groei)stadium, met de daarmee samenhangende hoge informatiekosten. Het is lastig dergelijke onzekerheden en eventualiteiten te vangen in een horizonbe-

13. Zie daarover ook A.A. Bootsma \& T.A. Keijzer, Snap Inc. De eerste beursgang met stemrechtloze aandelen in de VS, Ondernemingsrecht 2017/68.

14. Zie E.F. Fama \& K.R. French, Financing decisions: Who issues stock?, Journal of Financial Economics (76) 2005, afl. 3, p. 549-582. paling. Horizonbepalingen zijn kortom een oplossing, maar volgens Keijzer niet de oplossing.

Een - volgens Keijzer meer dynamisch - alternatief voor het opnemen van horizonbepalingen in de statuten is een zogenoemd 'put/call-mechanisme'. ${ }^{15}$ Het idee van het put-aspect is dat een vennootschap de controlerende aandeelhouder een premie ten opzichte van de beurskoers geeft als hij zijn aandelen verkoopt aan een andere aandeelhouder of de vennootschap. De controlerende aandeelhouder heeft dan een prikkel om de dual class-aandelenstructuur af te breken. Het callaspect bevat juist een prikkel om een dual class-aandelenstructuur op te tuigen. Een aandeelhouder die vindt dat een vennootschap onbenutte potentie heeft, kan een voorstel doen (ook midstream) om door een statutenwijziging een dual classaandelenstructuur in te stellen.

De moraal van het verhaal van Keijzer is dat institutionele beleggers minder krampachtig zouden moeten reageren op dual class-aandelenstructuren. ${ }^{16}$ Een herwaardering daarvan is in feite niet meer dan logisch.

\section{Erik Vermeulen over 'Coding for Lawyers'}

Professor Erik Vermeulen sloot de middag af met een inspirerend en prikkelend verhaal over 'Coding for Lawyers'. ${ }^{17} \mathrm{De}$ titel van de presentatie is echter misleidend. Vermeulen bepleit namelijk niet dat juristen zelf moeten coderen, maar dat juristen moeten samenwerken met coders bij het schrijven van algoritmes. Maar waarom is het nu eigenlijk noodzakelijk dat juristen en techneuten samen om de tafel gaan zitten?

In december 2016 stuitte Vermeulen op een artikel van Christoph Jentzsch over volledig geautomatiseerde vennootschappen, ofwel 'Decentralized Autonomous Organizations' (hierna: DAO's). ${ }^{18}$ Een DAO bestaat op basis van een code. Door deze code kan de DAO volledig zelf functioneren. Alles verloopt volgens de voorgeprogrammeerde code, die als de statuten van de 'vennootschap' fungeert. Voor de DAO geldt dat de code wet is. Aangezien niet van de code kan worden afgeweken, is er geen ruimte voor de redelijkheid en billijkheid. In 2016 is de DAO 'gehackt', doordat een slimme coder misbruik wist te maken van mazen in de code. De code voorzag namelijk niet in beperkingen op de oprichting van 'dochters' van de DAO van Jentzsch. De coder richtte aldus een dochter op en maakte daarna USD 50 miljoen over naar de dochter -

15. Zie http://clsbluesky.law.columbia.edu/2019/01/02/dual-class-common -stock-an-issue-of-public-and-private-law/.

16. Zie ook T.A. Keijzer, Having your cake and eating it, too. Over het weren van dual class-structuren uit aandelenindices, $\mathrm{MvO} 2018$, afl. 8-9, p. 223-231.

17. Prof. mr. E.P.M. (Erik) Vermeulen is Senior Legal Counsel bij Signify (voorheen: Philips Lighting) te Eindhoven. Daarnaast is hij hoogleraar Ondernemingsrecht en Financieel recht aan Tilburg University en Tilburg Law and Economics Center.

18. C. Jentzsch, Decentralized Autonomous Organization to automate governance, Slock.it 2016, https://download.slock.it/public/DAO/ WhitePaper.pdf. 


\section{Maandblad}

hetgeen de code ook niet verbood. De coder had de dochter zo ingericht dat alleen hijzelf bij het geld kon.

Dit voorval bracht Vermeulen op het idee om juristen en coders dichter bij elkaar te brengen. Juristen kunnen immers helpen om dergelijke mazen in de code voor te zijn door hun inzicht in het functioneren van de maatschappij en het bedrijfsleven. Door samen te werken kunnen beiden slimmer worden. Dit is volgens Vermeulen om verschillende redenen noodzakelijk. De DAO was mislukt, maar de mislukking was voor coders geen reden om te stoppen met het ontwikkelen van codes voor volledig geautomatiseerde vennootschappen. Er is immers veel vraag naar. Dit houdt verband met de steeds belangrijkere rol die technologie en automatisering spelen in de maatschappij en het recht. Zo worden smart contracts steeds meer verfijnd en kan blockchain het vennootschapsrecht verbeteren door ownership-structuren transparant te maken, clearing en settlement efficiënter te maken en stemmen in algemene vergaderingen te stroomlijnen. Ook de overheid steekt veel geld in technologische ontwikkeling en automatisering. De belangrijkste reden is echter de behoefte in de maatschappij naar vlakkere organisaties. Vermeulen wijst bijvoorbeeld op platformbedrijven. Corporate governanceregels passen echter niet in de platforms en behoeven aanpassing. De volgende stap is dan ook dat bedrijven volledig worden aangestuurd door een algoritme.

Is dit alles nu beangstigend of niet? Vermeulen meent van niet. In 1995 zei Steve Jobs het volgende:

'Everybody in this country should learn how to program a computer ("code") (...), because it teaches you how to think. It's like going to law school. I don't think anyone should be a lawyer, but going to law school can actually be useful because it teaches you how to think in a certain way.' ${ }^{19}$

Kortom, waar de maatschappij op dit moment behoefte aan heeft, zijn personen die juridisch onderlegd zijn en tevens vooruit durven te kijken.

19. Interview van Robert Cringely voor PBS met Steve Jobs in 1995, Triumph of the nerds. Zie www.youtube.com/watch?v=O3ODaAJsiNs. 